\title{
COVID's reckoning: A crack in everything, and the light got in
}

Norman E. Taylor*

\author{
Ring the bells that still can ring \\ Forget your perfect offering \\ There is a crack a crack in everything \\ That's how the light gets in
}

From Anthem (Cohen 1992)

About two weeks after the lockdowns began in response to the COVID-19 pandemic, a major Canadian financial paper ran a headline that said, in part, "From Nobodies to Essential Workers" (Subramaniam 2020). The reference was to truckers, and in fairness to the journalist (but not so much to the tone-deaf editorial team) she was quoting the awkward observations of one driver on the new levels of attention and appreciation they were receiving. About six weeks further along, Registered Nurse Lauren Bailey wrote in a Toronto Star opinion piece, " ... for me as a front-line worker, there is this itching paradox that has been rubbing me the wrong way. I am suddenly not "just a nurse." I am now a front-line worker and a supposed health-care hero. Unexpectedly, I am skipping lines, getting greatly appreciated discounts, pay raises, nightly standing ovations, and for the first time I'm feeling like I get the recognition that we deserve" (Bailey 2020).

It was around the time of the second article that I began to notice a common phrasing showing up on my social media feeds, to the effect that, "We sure are learning who the important people are." As much as both articles referenced above made me uncomfortable, it was that ugly sentiment that made me truly angry. "No, we are not!," was my offended reaction. "Hopefully, some might be learning how wrong it has been to ever consider any of these people ... indeed any people ... as unimportant." As the popular meme goes, "It's not pie!" A slice of respect for some should never deny or diminish the respect due to others.

But it has, hasn't it? For far too long, our global society has heralded the rich, the privileged, the powerful, while variously exhibiting, or passively tolerating, continuing levels of disregard, disrespect, and disempowerment of the everyman and everywoman. As more recent weeks have again thrown into vivid relief, even this is a sliding scale that still favours some, provides a tolerable stasis for others, while it metes out a brutal daily injustice for many, notably black and indigenous people, other people of colour, and other marginalized communities.

In my darker moods during this quarantine, I find I can neither reconcile nor quell my anger that any 21st-century human services system, and its multiple sub-systems, could have remained so blind and intractable for so long in the face of ample public health evidence, smarter social policy knowledge, and deafening, passionate appeals for justice, equity, and access. In clearer moments, I lean back on the basic optimism that has informed and guided my professional career. And here I recognize that, while none of this should be a surprise to anyone, we must seize upon this rare opportunity with all our might, before the crack heals over again and the darkness returns for more decades to come.

In her recent research into the barriers to real action on global warming, Lisa Taylor (2020) traces and examines decades of evidence that may also shed some light on the social policy intractability that recent events might now be dislodging in real time. Coining a new term "Contemporary Latent Neoliberalism," she offers four basic tenets that appear to have shaped, and which might explain, ongoing resistance to real and necessary progress in both our environmental and social systems. According to her study, they are globally evident as the following:

1. A focus on free-market capitalism (with the concept of infinite and continued growth, leading to an almost singular focus on shareholder value as the key economic driver and measure of success);

2. Light-touch by government (focused only on protecting the market from democratic challenges);

3. The hidden ruling elite (which includes think tanks, foundations, and academia using publications and social media as tools to produce and proliferate information specifically designed to steer the economy in the desired direction as and when necessary; and,

4. Social issues (including the environment) as subordinate to all else. (p. 36)

\footnotetext{
Correspondence to: Norman E. Taylor, Journal of Community Safety \& Well-Being, Community Safety Knowledge Alliance (CSKA), 120 Sonnenschein Way-Main, Saskatoon, SK S7M OW2. E-mail: ntaylor@cskacanada.ca

To cite: Taylor, N. E. (2020). COVID's reckoning: A crack in everything, and the light got in. Journal of Community Safety and Well-Being, 5(2), 29-30. https://doi. org/10.35502/jcswb.145
}

(C) Author(s) 2020. Open Access. This work is distributed under the Creative Commons BY-NC-ND license. For commercial re-use, please contact sales@sgpublishing.ca.

gg PUBLISHING Published by SG Publishing Inc. CSAA Official publication of the Community Safety Knowledge Alliance. 
Only time will tell how much the first three of these tenets might be ready to shift. But, the fourth is the one that will resonate immediately and viscerally for most of us working in community safety and well-being. It is also the one that has almost immediately changed, or at least revealed a new ability to change, during the recent crisis.

Within weeks of the pandemic declarations around the world, we witnessed almost daily examples of public policymakers, political leaders, and even financial barons switching off their more predictable patterns of "No, we can't" and "No, you mustn't." Instead, amid a sudden respect for, or perhaps merely a fear-induced new reliance upon, our public sector institutions (heretofore neglected whenever and to whatever extent possible), these reflex responses fell like dominoes, and changed to "Yes, we can," "Yes, we will," and "Please ... yes, we must."

Authorized work-from-home arrangements? Curbside pick-up shopping? Sanitized public spaces? Yes, we can. Safe housing for the homeless? Harm-reduction measures for the addicted? Expanded budgets, ramped up supplies, and wage top-ups for essential workers? Yes, we will. Economic assistance to individuals, small businesses, renters? Basic decency for elders and long-term care residents? Yes, it seems, we must. Elevate the importance of listening to public health professionals? "Damn, I guess we better."

Enter phase two. As of this writing, we are now weeks into the searing and tragic images of the murder of George Floyd, and the largest-in-decades, continuing, and mostly peaceful demonstrations, supplanting coronavirus fears while laying bare the toxic and lethal anti-black and antiindigenous racism, amid all the other shameful inequalities of our modern society.
The light got in. Better ways are possible. "No, we can't" or, too often more truthfully, "No, we simply don't want to," will just not cut it anymore.

We will recover from COVID-19. Let's never recover from our long overdue awakening.

\section{CONFLICT OF INTEREST DISCLOSURES}

The author has continuing business interests that include providing advisory services to communities, police services and related human service agencies.

\section{AUTHOR AFFILIATIONS}

*Editor-in-Chief, Journal of Community Safety and Well-Being

\section{REFERENCES}

Bailey, L. (2020). Suddenly, I'm not just a nurse. Toronto Star. Retrieved June 8, 2020, from https://www.thestar.com/opinion/contributors /2020/05/11/suddenly-im-not-just-a-nurse.html

Cohen, L. (1992). Anthem. Produced by Leonard Cohen and Rebecca De Mornay.

Subramaniam, V. (2020). "From nobodies to essential workers": Truckers now key to getting goods on empty shelves in the coronavirus crisis. Financial Post. Retrieved June 8, 2020, from https://business. financialpost.com/news/retail-marketing/from-nobodies-to-essentialworkers-truckers-now-key-to-getting-goods-on-empty-shelves-in-thecoronavirus-crisis? utm_medium=Social\&utm_source $=$ Twitter\#Echo box $=1585341180$

Taylor, L. (2020). Addressing anthropogenic climate change: How contemporary latent neoliberalism is getting in the way. Unpublished manuscript. Masters Department in Design: Strategic Foresight and Innovation. Ontario College of Art and Design University (OCADU). Toronto, Ontario. 